\title{
A novel mutation in C5L2 gene was associated with hyperlipidemia and retinitis pigmentosa in a Chinese family
}

\author{
Ling-hui Qu', Xin Jin ${ }^{1,2}$, Liang-mao $\mathrm{Li}^{3}$, Shi-ying Li ${ }^{1 *}$ and Han-ping Xie ${ }^{1 *}$
}

\begin{abstract}
Background: Previous studies indicated that hyperlipidemia was associated with retinitis pigmentosa (RP). We aimed to identify the mutations in the C5L2 gene which was reported to be associated with hyperlipidemia in a Chinese family with (RP).

Methods: The Proband from the family was screened for mutations in the C5L2 gene that was known to cause hyperlipidemia. Cosegregation analysis was performed in the available family members. Linkage analysis was performed for one missense mutation to calculate the likelihood of its pathogenicity. One hundred and fifty unrelated, healthy Chinese subjects were screened to exclude nonpathogenic polymorphisms.

Results: By direct sequencing method, we identified a novel mutation (Thr196Asn) in C5L2 gene. In this family, each affected family members with RP showed a heterozygous mutation in the C5L2 gene. And all the carriers with heterozygous mutation have increased serum lipid levels in this family.

Conclusions: The present study has extended the mutation spectrum of C5L2, and Thr196Asn mutations in C5L2 were associated with RP and serum lipid levels.
\end{abstract}

Keywords: C5L2, Mutation, Retinitis pigmentosa

\section{Introduction}

Retinitis pigmentosa (RP) is a hereditary retinal degeneration of unknown etiology, resulting in progressive night blindness, loss of peripheral vision, abnormal retinal pigmentation and reduced electroretinographic response [1]. Nonsyndromic RP is the most common inherited form of severe retinal degeneration, with a prevalence of approximately $1 / 4,000$ RP cases worldwide [1]. Nonsyndromic cases can be inherited as an autosomal-dominant $(20 \%-25 \%)$, autosomal-recessive $(15 \%-20 \%)$, X-linked recessive $(10 \%-15 \%)$, or sporadic/ simplex (30\%) trait [2].

Although there are more than 55 genes have been reported to be associated with RP, the mechanism of $\mathrm{RP}$ remains unclear. The previous studies suggested that lipid metabolism was abnormal in patients with

\footnotetext{
*Correspondence: zhengqin@163.com; xiehanping955@163.com

'Southwest Eye Hospital, Southwest Hospital, Third Military Medical

University, 30 Gaotanyan Road, Chongqing 400038, China

Full list of author information is available at the end of the article
}

RP [3,4]. And Fujita et al. reported an association between a missense coding region polymorphism Asn985Tyr in the retinitis pigmentosa 1 gene (RP1), a causal gene for $\mathrm{RP}$, and plasma triglyceride (TG) levels in 332 adult Japanese [5]. These evidences suggested that abnormal metabolism of lipids may be associated with the RP patients. C5L2 is a G protein-coupled receptor (GPCR) and was demonstrated to be a functional receptor of acylation-stimulating protein (ASP) [6-8]. ASP is also known as C3a des-Arg, a stimulator of TG synthesis [9-12] or glucose transport [13,14]. Previous study suggested that genetic mutation of C5L2 was associated with hyperlipidemia $[15,16]$. Therefore, we hypotheses that the mutation in C5L2 gene is associated with risk for RP.

In the present study, we aimed to identify novel mutations in C5L2 gene in a RP family and to analyze the relation between this mutation and RP. 


\section{Methods}

\section{Recruitment of subjects}

All participants were identified at Southwest Eye Hospital, the General Hospital of Chinese People's Liberation Army. The diagnosis of RP was based on the presence of night blindness, typical fundus findings (characteristic retinal pigmentation, vessel attenuation, and various degrees of retinal atrophy), the severe loss of peripheral visual field, and abnormal electroretinogram (ERG) findings (dramatic diminution in amplitudes or the complete absence of response). Figure 1(A) showed the fundus pictures of the right (R) and left eye (L) of the index patient. ERG testing showed non-recordable responses (Figure 1B). This study was approved by the Institutional Review Board of Southwest Hospital, the General Hospital of Chinese People's Liberation Army and adhered to the tenets of the Declaration of Helsinki and the Guidance on Sample Collection of Human Genetic Diseases by the Ministry of Public Health of China.

\section{Clinical evaluations}

For each patient, a full medical and family history was taken and an ophthalmological examination was performed. Each underwent a standard ophthalmic examination: best correct visual acuity according to Snellen charts, slit-lamp biomicroscopy, dilated indirect ophthalmoscopy, fundus photography if possible, and visual field tests (Octopus; Interzeag, Schlieren, Switzerland). Retinal structure was examined by using optical coherence tomography (OCT; Topcon, Tokyo, Japan). ERGs were performed (RetiPort ERG system; Roland Consult, Wiesbaden, Germany) using corneal "ERGjet" contact lens electrodes. The ERG protocol complied with the standards published by the International Society for Clinical Electrophysiology of Vision.

\section{Biochemical analysis}

Serum concentrations of total cholesterol (TC), Triglycerides (TG), glucose, high-density lipoprotein cholesterol (HDL-C), Low-density lipoprotein cholesterol (LDL-C) were measured using standard methods.

\section{Genetic studies}

Genomic DNA was extracted from the peripheral white blood cells. We used $2 \mathrm{ml}$ blood which collected in EDTA vacutainer tubes. Genomic DNA was isolated from the peripheral leukocytes by using a QIAamp DNA Blood Midi Kit (Qiagen, Hilden, Germany) according to the manufacturer's protocol. All 2 coding exons of the C5L2 gene were sequenced. Sequence information for use as a reference template was obtained from the Ensembl Genome Browser (Human, number ENSG00000134830). Sequencing primers were described by Zheng et al. [15,16]. The sense primer was $5^{\prime}$ AAGATGCCACTTCTA ACAACA3' and the antisense primer was 5'GTTGAATGAAGGAAGGAATAA3'. The PCR procedure was described previously [16]. Briefly, the polymerase chain reaction (PCR) was undertaken with $50 \mathrm{ng}$ of genomic DNA in a $20 \mu \mathrm{L}$ reaction containing $10 \mu \mathrm{L}$ of Power Mix (Beijing Biotech, Beijing, China), $9.5 \mu \mathrm{L}$ of distilled water, and $0.2 \mathrm{mM}$ of each forward and reverse primer. A GeneAmp 9700 thermal cycler (Applied Biosystems, Foster City, CA, USA) was used for PCR amplification. An initial denaturation step at $95^{\circ} \mathrm{C}$ for $5 \mathrm{~min}, 40$ cycles of $95^{\circ} \mathrm{C}$ for $30 \mathrm{~s}, 56^{\circ} \mathrm{C}$
A

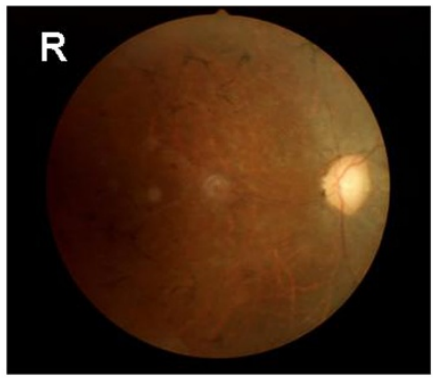

$250 \mu$ v/div

B

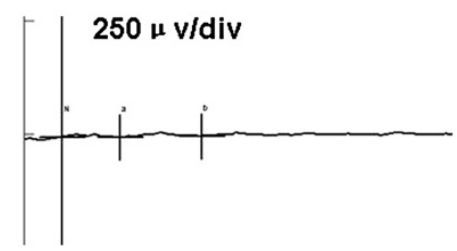

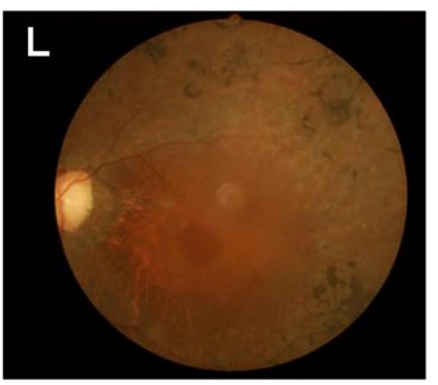

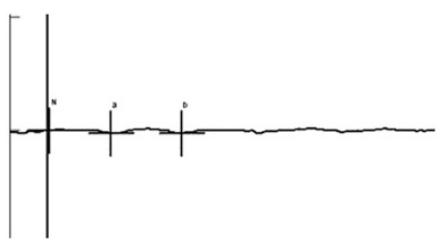

Figure 1 Morphological findings. A. Fundus pictures of the right $(R)$ and left eye $(L)$ of the index patient showing pallor optic discs, attenuated vessels, and characteristic pigment changes in the mid-periphery. B. ERG testing showed extinguished rod response. 
for $30 \mathrm{~s}$, and $72^{\circ} \mathrm{C}$ for $1 \mathrm{~min}$ was followed by a final extension step of $72^{\circ} \mathrm{C}$ for $10 \mathrm{~min}$. A 1615-base pair (bp) product was amplified was purified using ExoSAP-IT (Amersham Biosciences) according to manufacturer's instructions before it was used as a template for sequencing. Sequencing reactions were undertaken by BGI-Beijing (Beijing, China; http://www.genomics.cn).

\section{Statistical analysis}

Data were analyzed using SPSS software 13.0. Statistical significance was accepted at $p<0.05$. Values were expressed as mean \pm SD for serum concentrations of TC, TG, HDL-C and LDL-C. Student's t-test was performed to compare serum lipids levels between mutation carriers and wild carriers.

\section{Results}

\section{Mutation analysis}

Upon complete sequence analysis of the coding regions of C5L2, three mutations were detected in four (RP patients) out of 16 family members, including one novel missense mutation (Thr196Asn) and two previously reported missense mutation (Pro233Leu, and rs36046934). The missense mutation c.587C $>\mathrm{A}$ in exon 1 resulted in a substitution of asparagine for threonine at codon 196 (Thr196Asn). This novel mutation (Thr196Asn) has not been found in 150 unrelated healthy subjects.

\section{The relation between novel mutation and RP}

In this family, we found all these four patients with RP were carriers of 196Asn allele, but the else 10 unaffected members were not carriers with 196Asn allele (Figures 2 and 3).
The relation between novel mutation and lipids level In this family, we also found the carriers with 196Asn allele have higher levels of TG $(2.9 \pm 1.3 \mathrm{mmol} / \mathrm{L})$ and LDL-C $(5.1 \pm 1.4)(p<0.05)$. However, the subjects without 196Asn allele have lower levels of serum lipids (TG, $1.6 \pm 0.4$; LDL-C, $3.3 \pm 1.1)(p<0.05)$ (Figure 4).

\section{Discussion}

In the present study, we identified a novel missense mutation (Thr196Asn) in a RP family, and found this variant affects the risk for RP and hypertriglyceridemia. This is the first study to identify a novel mutation and analyze the relation between this mutation and RP.

The foundation for human studies examining putative causative genes that may be involved in RP is based on a candidate gene approach. A few studies into the genetic polymorphisms of the C5L2 receptor located on chromosome 19q13 (the region identified to be associated with familial combined hyperlipidemia and the pre-diabetic state by genome-wide scan studies) have been completed $[17,18]$. Familial combined hyperlipidemia is considered to be the most frequent lipoprotein disorder in RP [3-5]. Therefore, the C5L2 gene is thought to be a candidate gene for RP.

In the present study, we identified three missense mutations in a family with RP. The Pro233Leu mutation was found by Zheng et al. in coronary artery disease (CAD) patient. Zheng et al. found the Pro233Leu variant was associated with CAD and Type 2 diabetes. The other variant- rs36046934 have been recorded in the NCBI database (http://www.ncbi.nlm.nih.gov/SNP). Therefore, in the present study, we did not analyze the relation between these two variants and RP. As for the mutation Thr196Asn, we did not find in 150 unrelated healthy subjects, which indicated that this mutation is a rare variant. In this RP family, all these four patients with RP have this

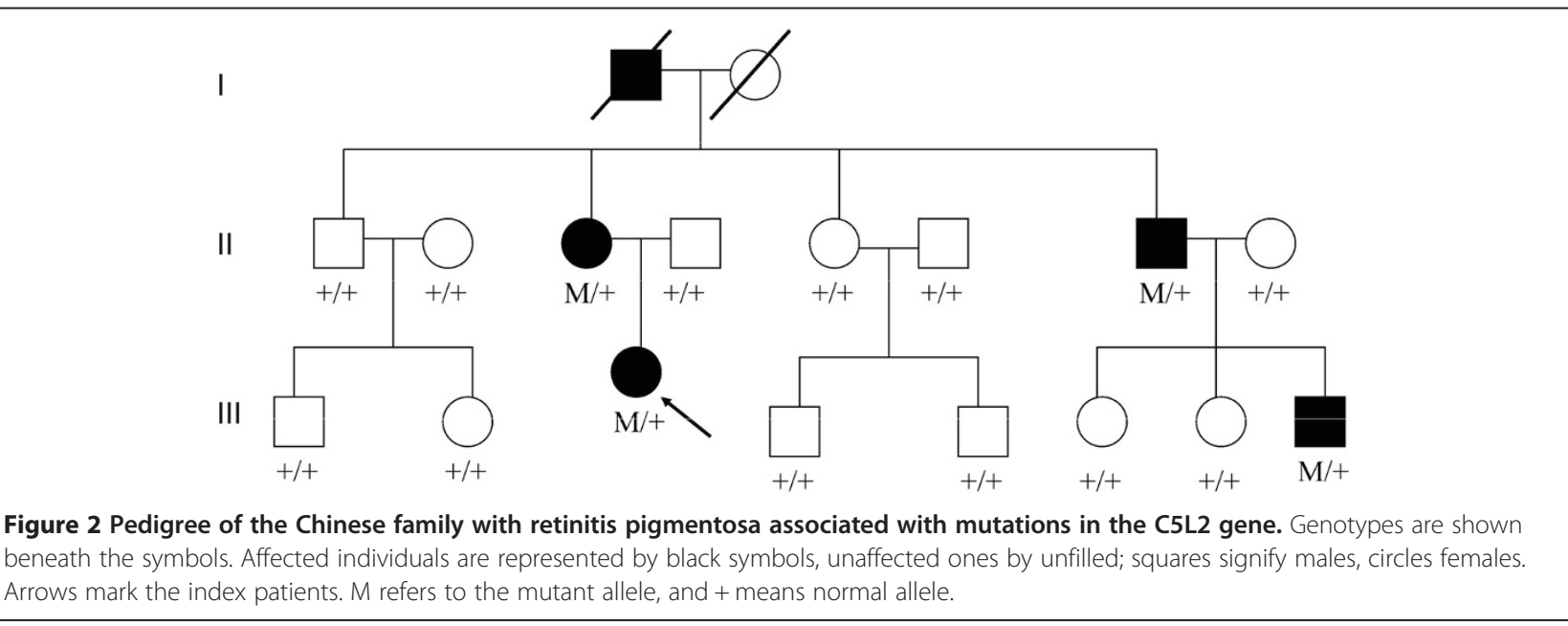


A
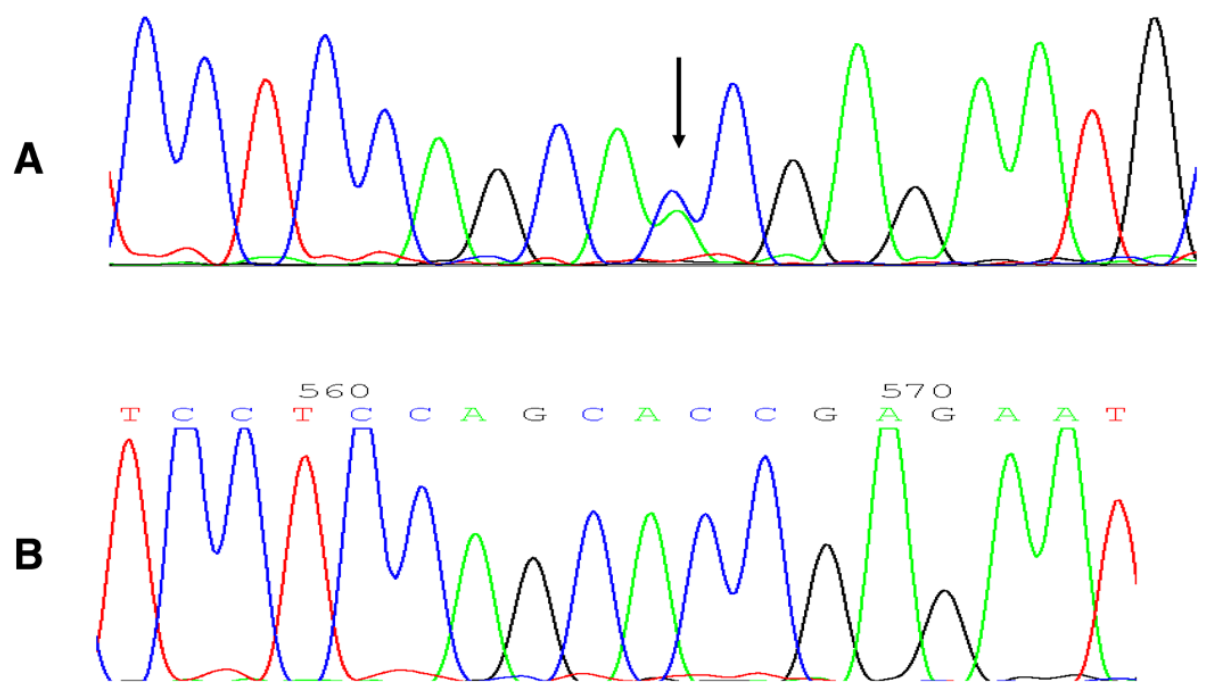

Figure 3 The DNA sequence around the mutation site. A: Mutation sequence; $\mathbf{B}$ : wild sequence.

mutation and the other eight members without RP have not this mutation, which suggested that the Pro233Leu variant is a causative mutation for RP in this family.

In addition, we also found the Pro233Leu variant was associated with increased TG and LDL-C levels in this family. However, the mechanisms may link to the RP and abnormal lipid level resulting from the C5L2 mutation is unclear and is worth exploring in the future.

\section{Conclusion}

In conclusion, the C5L2 may be a causative gene for RP with hyperlipidemia.

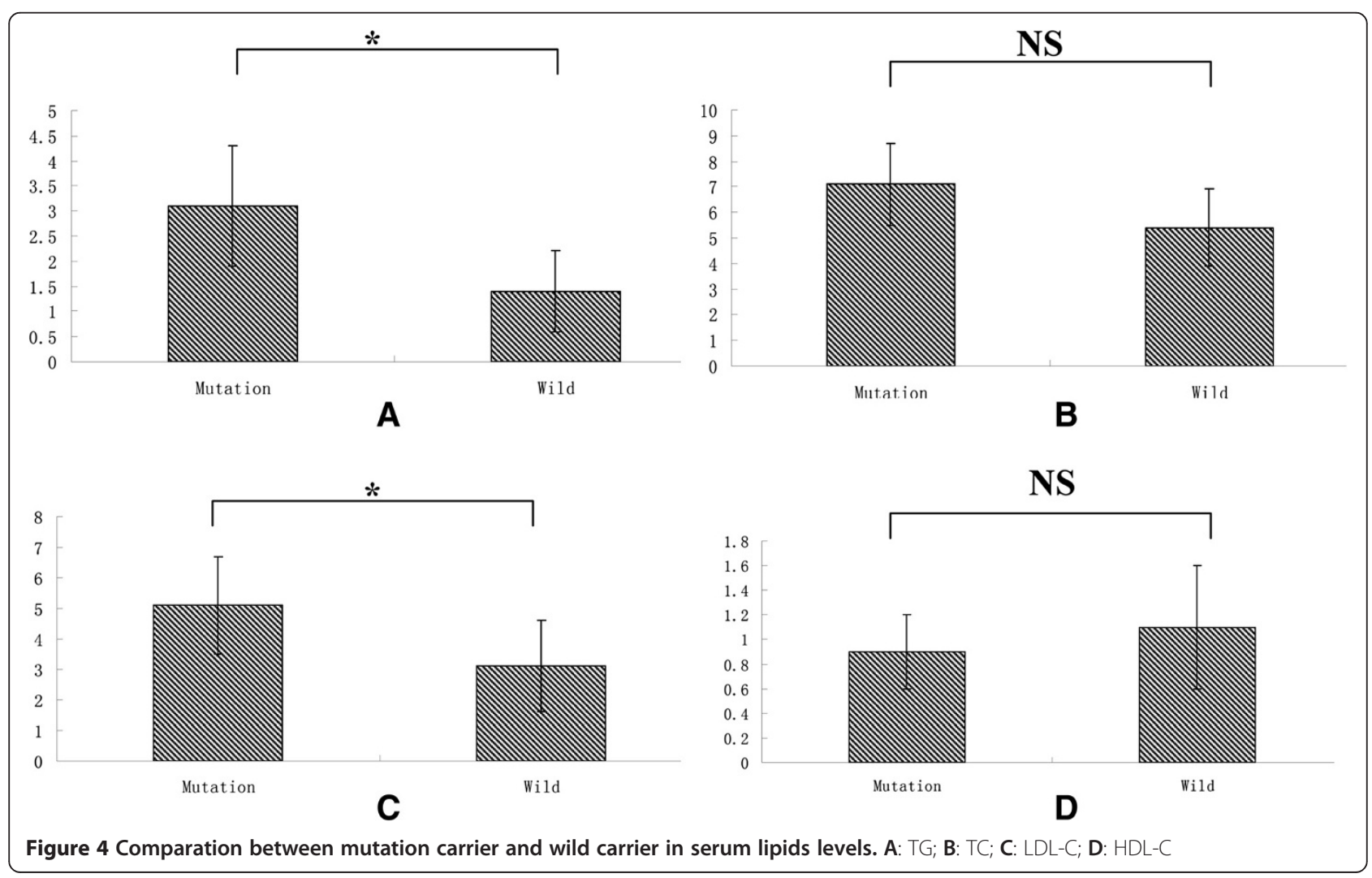




\section{Competing interests}

The authors declared no competing interests exist.

\section{Authors' contributions}

$\mathrm{LHQ}$ and $\mathrm{XJ}$ carried out the molecular genetic studies and drafted the manuscript. QLH and LML carried out the genotyping. ZQY, HPX and SYL participated in the design of the study and performed the statistical analysis. All authors read and approved the final manuscript.

\section{Authors' information}

Ling-hui Qu and Xin Jin co-first authors.

\section{Acknowledgments}

This study was supported by the National Natural Sciences Foundation of China (No.81172873) and the National Basic Research Program of China (No.2013CB967002).

\section{Author details}

'Southwest Eye Hospital, Southwest Hospital, Third Military Medical University, 30 Gaotanyan Road, Chongqing 400038, China. ${ }^{2}$ Department of Ophthalmology, Chinese PLA General Hospital, Beijing 100853, China. ${ }^{3}$ Department of Ophthalmology, No. 181 Hospital of Guilin, Guilin 541002, China.

Received: 20 February 2014 Accepted: 22 April 2014

Published: 6 May 2014

\section{References}

1. Berger W, Kloeckener-Gruissem B, Neidhardt J: The molecular basis of human retinal and vitreoretinal diseases. Prog Retin Eye Res 2010, 29:335-375.

2. Ferrari S, Di lorio E, Barbaro V, Ponzin D, Sorrentino FS, Parmeggiani F: Retinitis pigmentosa: genes and disease mechanisms. Curr Genomics 2011, 12:238-249.

3. Holman RT, Bibus DM, Jeffrey GH, Smethurst P, Crofts JW: Abnormal plasma lipids of patients with retinitis pigmentosa. Lipids 1994, 29:61-65.

4. Newsome DA, Anderson RE, May JG, McKay TA, Maude M: Clinical and serum lipid findings in a large family with autosomal dominant retinitis pigmentosa. Ophthalmology 1988, 95:1691-1695.

5. Fujita Y, Ezura Y, Emi M, Ono S, Takada D, Takahashi K, Uemura K, lino $Y$, Katayama Y, Bujo H, Saito Y: Hypertriglyceridemia associated with amino acid variation Asn985Tyr of the RP1 gene. J Hum Genet 2003, 48:305-308.

6. Cui W, Simaan M, Laporte S, Lodge R, Cianflone K: C5a- and ASP-mediated C5L2 activation, endocytosis and recycling are lost in S323I-C5L2 mutation. Mol Immunol 2009, 46:3086-3098.

7. MacLaren R, Kalant D, Cianflone K: The ASP receptor $C 5 L 2$ is regulated by metabolic hormones associated with insulin resistance. Biochem Cell Biol 2007, 85:11-21.

8. Kalant D, MacLaren R, Cui W, Samanta R, Monk PN, Laporte SA, Cianflone K: C5L2 is a functional receptor for acylation stimulating protein. $J$ Biol Chem 2005, 280:23936-23944.

9. Cui W, Lapointe M, Gauvreau D, Kalant D, Cianflone K: Recombinant C3adesArg/acylation stimulating protein (ASP) is highly bioactive: a critical evaluation of C5L2 binding and 3T3-L1 adipocyte activation. Mol Immunol 2009, 46:3207-3217.

10. Faraj M, Sniderman AD, Cianflone K: ASP enhances in situ lipoprotein lipase activity by increasing fatty acid trapping in adipocytes. J Lipid Res 2004, 45:657-666.

11. Xiang SQ, Cianflone K, Kalant D, Sniderman AD: Differential binding of triglyceride-rich lipoproteins to lipoprotein lipase. J Lipid Res 1999, 40:1655-1663.

12. Paglialunga S, Julien P, Tahiri Y, Cadelis F, Bergeron J, Gaudet D, Cianflone K: Lipoprotein lipase deficiency is associated with elevated acylation stimulating protein plasma levels. J Lipid Res 2009, 50:1109-1119.

13. Saleh J, Al-Khanbashi M, Al-Maarof M, Al-Lawati M, Rizvi SG, Cianflone K. Acylation-stimulating protein increases and correlates with increased progesterone levels during the luteal phase of the menstrual cycle. Eur J Endocrinol 2009, 160:301-307.

14. de Lind van Wijngaarden RF, Cianflone K, Gao Y, Leunissen RW, Hokken-Koelega AC: Cardiovascular and metabolic risk profile and acylation-stimulating protein levels in children with Prader-Willi syndrome and effects of growth hormone treatment. J Clin Endocrinol Metab 2010, 95:1758-1766.
15. Zheng $Y Y$, Xie X, Ma YT, Yang YN, Fu ZY, Li XM, Ma X, Chen BD, Liu F: A novel polymorphism ( $901 \mathrm{G}>\mathrm{a}$ ) of C5L2 gene is associated with coronary artery disease in Chinese Han and Uyghur population. Lipids Health Dis 2013, 12:139.

16. Zheng YY, Xie X, Ma YT, Yang YN, Fu ZY, Li XM, Ma X, Chen BD, Liu F: Relationship between a novel polymorphism of the C5L2 gene and coronary artery disease. PLoS One 2011, 6:e20984.

17. Huerta-Vazquez A, Aguilar-Salinas C, Lusis AJ, Cantor RM, Canizales-Quinteros S, Lee JC, Mariana-Nuñez L, Riba-Ramirez RM, Jokiaho A, Tusie-Luna T, Pajukanta $P$ : Familial combined hyperlipidemia in Mexicans: association with upstream transcription factor 1 and linkage on chromosome 16q24.1. Arterioscler Thromb Vasc Biol 2005, 25:1985-1991.

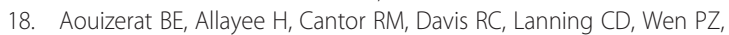
Dallinga-Thie GM, de Bruin TW, Rotter Jl, Lusis AJ: A genome scan for familial combined hyperlipidemia reveals evidence of linkage with a locus on chromosome 11. Am J Hum Genet 1999, 65:397-412.

doi:10.1186/1476-511X-13-75

Cite this article as: Qu et al:: A novel mutation in C5L2 gene was associated with hyperlipidemia and retinitis pigmentosa in a Chinese family. Lipids in Health and Disease 2014 13:75.

\section{Submit your next manuscript to BioMed Central and take full advantage of:}

- Convenient online submission

- Thorough peer review

- No space constraints or color figure charges

- Immediate publication on acceptance

- Inclusion in PubMed, CAS, Scopus and Google Scholar

- Research which is freely available for redistribution

Submit your manuscript at www.biomedcentral.com/submit
C Biomed Central 